\title{
Effective use of an Undergraduate Research Fellowship for Design and Man- ufacture of Tools to Assist in Teaching Strength of Materials
}

\section{Mr. Jacob Lee Finley}

Jacob Finley came to the University of Southern Maine in spring 2010. He is majoring in Mechanical Engineering. Finley became fascinated with mechanical properties of materials after taking a class with Dr. Ghorashi and observing the applications of the subject. He then teamed up with this professor and developed a way of demonstrating complex concepts in solid mechanics with easy to understand hands-on test set ups. Finley has always thoroughly enjoyed working on hands-on projects built from conception to execution. The main issue he addresses in his current research is developing ways to demonstrate mechanical behavior of structures and to measure the mechanical properties of materials to students in a way that is easy to understand.

\section{Prof. Mehrdaad Ghorashi P.E., University of Southern Maine}

Dr. Ghorashi is a member of the ASME and the ASEE. He is a licensed professional engineer in Maine and the author or co-author of more than 50 journal or conference papers. In 1995, after receiving his first $\mathrm{Ph}$.D. on dynamics of structures under moving loads, he joined the Mechanical Engineering Department of Sharif University of Technology. In 2004, Dr. Ghorashi moved to Canada where he worked in Carleton University as a postdoctoral fellow. He also taught or co-taught a few courses at Carleton for which he received the Best Professor Award from the Carleton Student Engineering Society. In 2006 he decided to earn a second $\mathrm{Ph} . \mathrm{D}$. He studied the dynamics of nonlinear rotating composite beams with embedded actuators and graduated in 2009. In September 2009, Dr. Ghorashi joined the Department of Engineering in the University of Southern Maine. He teaches strength of materials, statics, dynamics, machine design, machine dynamics, control systems and composites on a regular basis. 


\section{The Effective use of an Undergraduate Research Fellowship for Design and Manufacture of Tools to Assist in Teaching Strength of Materials}

In the Strength of Materials and Design of Machine Elements courses in a bachelor degree program of Mechanical Engineering students need to learn a lot of new concepts and formulations about the way materials and structures behave. Obtaining this information is critically important if they want to become successful engineers. Traditionally, these concepts have been taught in lectures using diagrams and formulations as well as referring students to textbooks. While these are all vital resources for the students, when they are integrated with hands-on experiences a significant progress in achieving the learning outcomes is observed. Even a brief hands-on experience goes a long way. Some students who get bored in a lecture setting, after gaining a personal experience related to the subject, suddenly become the most interested ones! A teacher can then use this momentum for helping students understand the related theories and formulations as well. The reason is because students observe that what they study in the lectures is not just intangible theory - the final outcomes, in fact, have realistic meanings that can be tested, touched and seen. Such experiences also provide a means for comparing theoretical and experimental results.

In order to address the mentioned need for hands-on experience, a summer Undergraduate Research Fellowship (URF) was awarded. The principal objective of this award was to design and build teaching aids for the Strength of Materials and Design of Machine Elements courses. As a result of this fellowship, among other activities, four devices have been designed, fabricated and tested. The first one has been developed for measuring the modulus of elasticity and Poisson's ratio of a few metallic samples. These material properties are obtained in a bending test by measuring normal strain components using two strain gauges located along and perpendicular to the longitudinal axis of a beam member made of the materials of interest. Performing this experiment provides a long-lasting understanding for students about what the physical meanings of modulus of elasticity and Poisson's ratio are. In another part of this activity, a test setup was built to demonstrate a very fundamental theorem, i.e. Maxwell's Reciprocity theorem. This test provides students with a physical understanding of this theorem and helps them comprehend what it really means and if it is, in fact, valid. Next, by building another test setup and measuring the corresponding shear strain values in torsion, the behavior of closed and open thin-walled members were compared. Finally, a test setup for analyzing stress patterns in a sample using photoelasticity was built. Since fall 2012, these devices have been used by students as part of hands-on labs that are integrated with the mentioned courses. In this way, students gain necessary hands-on and real-world experience about concepts that would otherwise be abstract and intangible. The received feedback from students has been positive and most of them have expressed that they enjoy learning the course material much more if it is accompanied with such activities. 
Keywords: Mechanical properties, Undergraduate Research Fellow, hands-on experience, stress analysis, Maxwell's reciprocity theorem

\section{Introduction}

This paper summarizes the activities of an Undergraduate Research Fellow (URF) during the summer of 2012. He (the first author) designed and built a few experimental setups and performed several experiments with the aim of using them in mechanical engineering courses. During these activities, the URF was supervised by the second author. The aim was to use these experiments as parts of a laboratory program for courses like Strength of Materials and Design of Machine Elements. In this way, students would gain necessary hands-on and real-world experience about concepts that would otherwise be abstract and intangible. These activities are continuations to those performed in the past ${ }^{1}$.

The value of hands-on experiments and how they strengthen learning has been discussed in many researches. In a large scale, multi-year, randomized study the learning activities and outcomes for hands-on, remotely operated, and simulation based educational laboratories in an undergraduate engineering course have been compared ${ }^{2}$. Each team of students conducted the experiments in one of the three formats. This study concluded that for the hands-on lab format, learning outcomes were higher when the lab team collected data sets as a group while for the remotely-operated labs individual data collection was best. Also, it was observed that working with real instead of simulated data may induce higher levels of motivation.

The need for hands-on experience and conceptual knowledge in engineering education was also the subject of another research ${ }^{3}$. Experiential learning can be used as a foundation for teaching and learning engineering. This study shows that creativity and innovative thinking can be nurtured through experiential learning.

Hands on experience is also needed in manufacturing education ${ }^{4}$. It is mentioned that the dynamic manufacturing environment with rapid changes in manufacturing processes requires hands-on experiences in the laboratories that have modularity, integrability, customization, and open structure as key features.

The role of hands-on experiments in the K-12 education has also been discussed ${ }^{5}$. In this research, the results of an educational initiative have been presented where graduate and undergraduate students guide K-12 students through a series of hands-on modules in a pharmaceutical operations laboratory. These interactive experiments motivate students and affect their learning abilities substantially.

The use a novel model of laboratory education, namely TriLab, has been the subject of another research $^{6}$. It is based on three access modes (hands-on, virtual and remote) to the laboratory experience. A review of the three modes is provided with highlights of advantages and disadvantages of each mode. The paper mentions that the virtual component of the TriLab has 
been mainly used in a preparation session for undergraduate students, while the remote component has been mainly used for demonstrating theory applicability in postgraduate courses.

An example of "learning by doing" for Automatics and Robotics courses is explained in another research ${ }^{7}$. Such experiences provide students with a deep understanding of the theoretical lessons. However, expensive equipment and limited time prevent teachers from having sufficient educational platforms. So, low cost and flexible solutions would be of great value. The paper then introduces a virtual and remote robotics lab called RobUALab as one such alternative.

Such economic pressures have forced several schools to create new systems of delivering laboratory education using simulations and remote-access laboratory systems ${ }^{8}$. Advocates of simulation ague that physical labs needlessly consume university space and time. However, proponents of hands-on laboratories argue that engineering students should be exposed to real environments. Remote labs have appeared as a third option. These labs are similar to simulation techniques in that they require minimal space and time, because the experiments can be rapidly configured and run over the Internet. But unlike simulations, they provide real data. This reference presents a model for comparing the effectiveness of these laboratory activities.

The focus of this paper is to describe the development of several hands-on labs for teaching courses on solid mechanics. One of the major activities was to design experiments in order to perform stress and strain analyses and as a result, obtain the mechanical properties of a few materials. In some experiments, strain gages were attached to flat bars and round tubes. Additionally, utilizing ASTM E-8, standardized tensile test samples were cut and tested in an Instron 5882 Universal Testing Machine to determine mechanical properties like yield strength, tensile strength, rupture point, Young's modulus, and Poisson's ratio. These results were then compared with each other and against the available data in the literature. The materials used in the experiments included aluminum 6061 alloy, 304 stainless steel round tube, C1018 cold-rolled steel, and A36 hot-rolled structural steel. The results were found to be most accurate in the bending of flat bars. Furthermore, determination of residual stresses in a polymer material was accomplished using cross polarized fluorescent light that displayed stress fringe patterns via birefringence. Finally, an experimental setup for demonstrating Maxwell's Reciprocity theorem was designed and built. The data obtained using this setup was close to the theoretical values.

These experiments have been integrated into two courses in the fall 2012 and spring 2013. The results of anonymous questionnaires indicate that many students feel more motivated in learning the course materials when such hands-on experiences are at hand.

\section{Photoelasticity}

The purpose of this experiment is to observe the residual stress patterns as well as their changes as the materials are being loaded and unloaded. Photo elasticity is a stress analysis technique that was first introduced in a publication by Tollenaar in $1945^{9}$. The technique is still used today in industry to perform stress analysis when calculation with alternative methods would be 
cumbersome. Photoelastic analysis operates on the principle of birefringence; this occurs when a ray of light splits into two refractive indices upon entering a transparent material. The cause of the splitting of the light can be applied or residual stresses. Normally these stress patterns cannot be seen, but can be made visible with a polarizer ${ }^{9}$. A polarizer is a special optical device that removes one of the two planes in which light vibrates. If two polarizers are placed at an orientation ninety degrees relative to each other, light will not pass through them. By placing a transparent material capable of birefringence between the polarizers, light that splits on the residual or applied stress in the material can be seen in the form of colored fringe patterns. As a result, stress patterns can be seen on the object and phenomena like stress concentration can be readily detected.

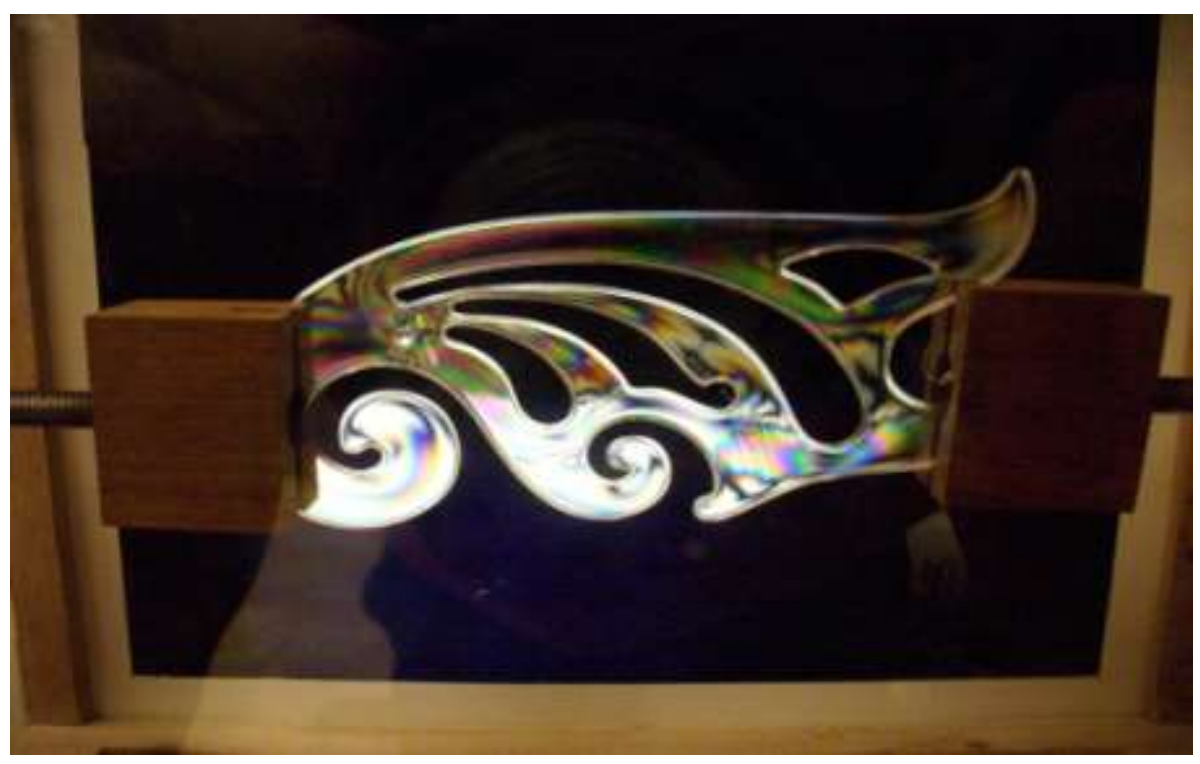

Figure 1. Residual stress patterns displayed by polarized light in a French curve

As is seen in figure 1, two frames were designed and built to hold the polarizing sheets; one rectangular and one circular. The second frame was made in the shape of an annulus or disc with a slit cut in the center to hold the polarizing sheet. This design was decided upon because of the need to rotate the frames relative to each other. The polarizing film was cut to shape for each frame. The polarizing sheets, however, would not stay in their frames and a rigid cardboard outline had to be made for each polarizer film. A platform and holding device was also designed and built for the test specimen. Next, a fluorescent light source was used to display residual stress patterns in a French curve.

The two polarizing frames were orientated at $90^{\circ}$ relative to each other so no light passed through them. The test specimen and platform were placed in between the polarizing frames and the 
florescent light was turned on. Immediately, stress patterns were observed and one could detect, for example, the point of injection of plastic in the French curve mold by noticing the point that has the highest stress concentration (at the upper-middle left of the part in figure 1). Also, as is expected, stress concentration is observed at points where the sample experiences sharp changes in geometry.

In the experiments performed by the students on this setup, they were asked to rotate the polarizer plates and observe the changes in the light that passes through the plates. Then, the students held a few transparent samples between the plates and observed the stress patterns. They were asked to answer questions like "How the stress concentration can be analyzed by these patterns?" and "Why there is stress in the materials when there is no loading?!" Finally, the students loaded the samples in bending and torsion and observed changes in the stress pattern.

\section{Elastic Bending of Flat Bars}

The goal of this experiment is to obtain Young's moduli or the moduli of elasticity of three materials as well as their Poisson's ratios using a non-destructive method. The modulus of elasticity of a material is of particular importance in engineering applications. This modulus is the slope of the linear region of the stress versus strain curve of a material. When a material is compressed in one direction (axial), it will usually expand in the perpendicular (transverse) directions. Poisson's ratio is the negative of the ratio of lateral strain to the axial $\operatorname{strain}^{10}$. Utilizing strain gauges, the goal of this experiment is to obtain the moduli of elasticity and Poisson's ratios of the following materials: C1018 cold-rolled steel, A36 hot-rolled steel, and 6061 aluminum.

For the experimental setup, the three samples were machined for surface smoothness and length. Mounting holes were drilled at the same locations on each sample. The surface of each sample was then cleaned, per the strain gauge glue manufacturer's instructions, and the sensors were attached on the samples in the lateral and axial orientations. In order to measure the moduli of elasticity, strain gauges are mounted on the samples along the axial orientation. Strain gauges are wired to an Omega DMD-21 single channel digital strain indicator, which measures the changes in the electrical resistance of the strain gauges due to deformation. As will be shown in the following equations, by having the cross sectional area of the samples, the distance of the load from the strain gauge, the magnitude of the applied load, and the resulting strain, the modulus of elasticity of each material can be calculated.

As is seen in figure 2, in order to use the one available strain gauge indicator channel for measuring strain values in six strain gauges (an axial and a lateral one per sample), each strain gauge is put in series with a switch and the sets of strain gauges and switches were set in parallel. 


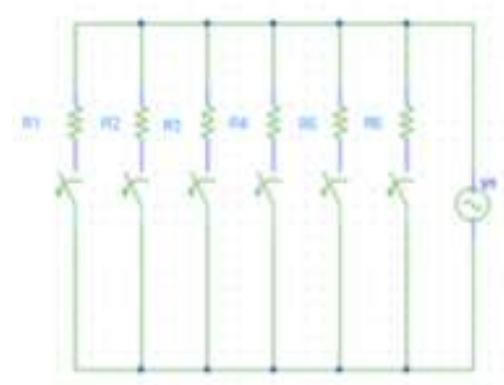

Figure 2. The strain sensor parallel circuit with six channels

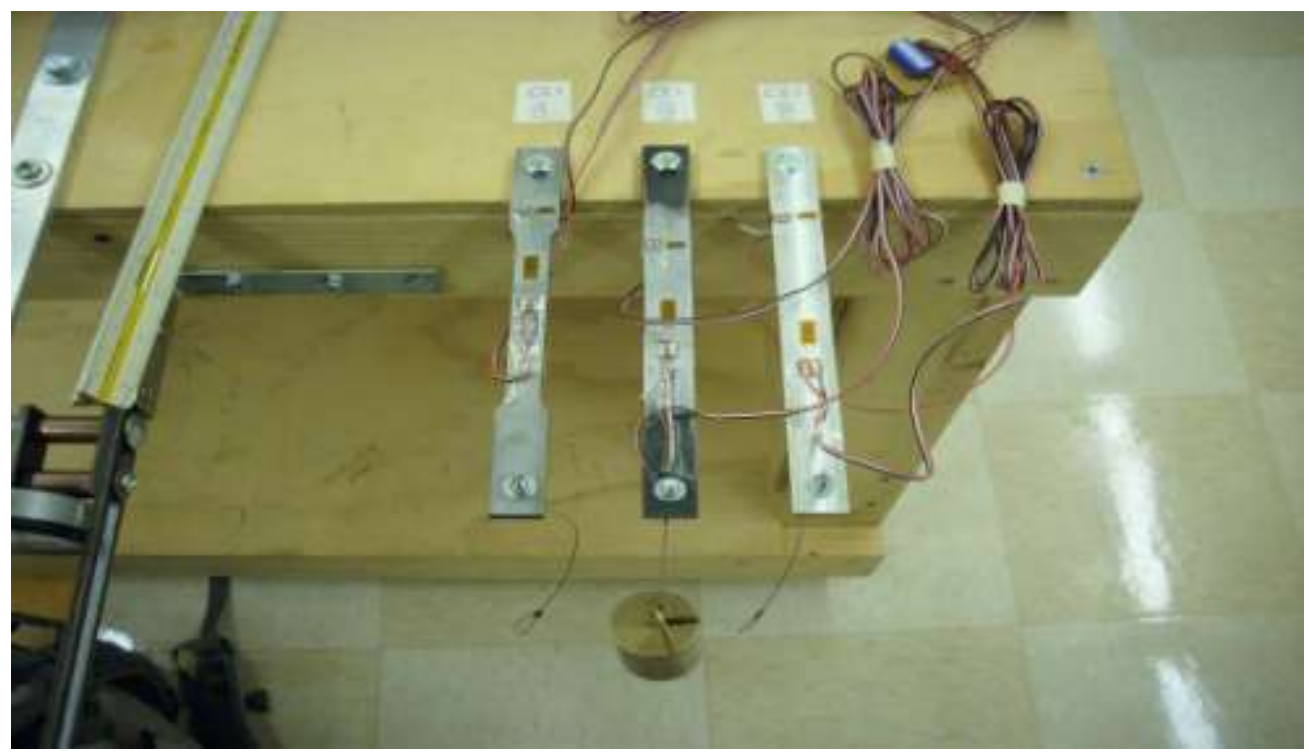

Figure 3. The three bending samples with attached strain gauges

Finally, as seen in figure 3, a loading device was designed and used to load each of the three samples with $1.05 \mathrm{~kg}$ of mass. Calipers were used to get an accurate measurement of the cross sectional area at the location of the axial strain gauges as well as the moment arm of the load i.e. the distance from the center of the axial strain gauge to the point of application of the load. Using the formulas listed below, the modulus of elasticity of all three materials as well their Poisson's ratios were calculated and listed in table 1 .

The modulus of elasticity can be obtained from Hooke's law that is:

$$
E=\frac{\sigma_{x}}{\varepsilon_{x}}
$$

where $\boldsymbol{\varepsilon}_{\boldsymbol{x}}$ is the axial strain and $\sigma_{x}$ is the axial stress. This stress is calculated from the pure bending equation, 
$\sigma_{x}=\frac{M c}{I}$

By substituting the bending moment, $M$, half the thickness, $c$, and the second moment of area, $I$, from table (1) into equation (2) one obtains,

$\sigma_{x}=\frac{(W d) h / 2}{\frac{1}{12} b h^{3}}$

Where, $W$ is the weight of the applied load at the tip of the beams (in all cases it is $1.05 \mathrm{kgf}$ ), $d$ is the distance between the point of application of the force and the center of the axial strain gauge, $b$ is the width and $h$ is the thickness of the samples. Therefore, the equation for the modulus of elasticity would be:

$E=\frac{6 W d}{b h^{2} \varepsilon_{x}}$

Table 1. Data for stress analysis of the bending test of flat bars

\begin{tabular}{|c|c|c|c|c|c|c|c|}
\hline Trial & & $\begin{array}{l}\text { Axial } \\
\text { Micro } \\
\text { itrain }\end{array}$ & $\begin{array}{l}\text { Lateral Micro } \\
\text { strain }\end{array}$ & $\begin{array}{l}\text { base } \\
\text { (b) }\end{array}$ & Height (h) & Distance (d) & $c=\frac{1}{2} h$ \\
\hline \multicolumn{8}{|c|}{ Cold rolled steel (CR1018) } \\
\hline & 1 & 66.5 & -14 & $0.013 \mathrm{~m}$ & $0.006 \mathrm{~m}$ & $0.12 \mathrm{~m}$ & $0.0032 \mathrm{~m}$ \\
\hline & 2 & 69 & -15 & & & & \\
\hline & 3 & 69 & -14.5 & & & & \\
\hline \multicolumn{8}{|c|}{ Hot rolled steel (A36) } \\
\hline & 1 & 41 & -14 & 0.019 & 0.006 & 0.11 & 0.0032 \\
\hline & 2 & 38 & -14 & & & & \\
\hline & 3 & 38 & -14 & & & & \\
\hline \multicolumn{8}{|c|}{ Aluminum (6061) } \\
\hline & 1 & 170.5 & -107 & 0.019 & 0.005 & 0.081 & 0.0025 \\
\hline & 2 & 171 & -107 & & & & \\
\hline & 3 & 172 & -107 & & & & \\
\hline $\begin{array}{l}\mathbf{E} \\
\text { (literature) }\end{array}$ & & $\begin{array}{l}\mathbf{E} \\
\text { (measured) }\end{array}$ & \% Difference & & & & \\
\hline \multicolumn{8}{|c|}{ Cold rolled steel (CR1018) } \\
\hline $200 \mathrm{GPa}$ & & $205.15 \mathrm{GPa}$ & 2.5 & & & & \\
\hline \multicolumn{8}{|c|}{ Hot rolled steel (A36) } \\
\hline $195 \mathrm{GPa}$ & & 190.13 & 2.5 & & & & \\
\hline \multicolumn{8}{|c|}{ Aluminum (6061) } \\
\hline 68 & & 63.2 & 8.27 & & & & \\
\hline
\end{tabular}

Now, for measuring Poisson's ratio the lateral strain gauge is also used and, having the lateral and the axial strain values, the Poisson's ratio is calculated by, 
$v=-\frac{\varepsilon_{y}}{\varepsilon_{x}}$

where $\varepsilon_{\boldsymbol{y}}$ is the lateral strain.

Using these equations, experimental values for the modulus of elasticity of the three cases of hot and cold-rolled steel and aluminum were obtained and presented in table 1 . These values are also compared with the corresponding data that is available in the literature. As is seen in the table 1, the calculated values of the modulus of elasticity for these materials are close to the corresponding values in the literature.

In the experiments, the students are supposed to follow the following procedure. Choose a sample and a strain gauge. Then, turn on the switch corresponding to the chosen strain gauge. Next, gently bend the sample and record the strain as well as the applied load. These steps are to be repeated for all six strain gauges. The results of these experiments are then used to calculate the modulus of elasticity and the Poisson's ratio these samples. In their report, students would compare their results for modulus of elasticity and Poisson's ratio with the data that they could find on tables for these materials.

\section{Elastic Bending and Torsion of Round Tubes}

The purpose of this experiment is to compare the mechanical properties of thin-walled closed and open tubes, as well as the values of the normal strain and shear strain that are induced in these tubes. Two tubes of the same length were cut and the ratio of the length to the diameter of the tubes was chosen to be large enough to make the beam assumption valid. The dimensions of the tubes are $d_{0}=52.15 \mathrm{~mm}$ and $l=609.6 \mathrm{~mm}$, where $d_{o}$ is the outer diameter and $l$ is the length. The thickness of the tubes is $t=1.7 \mathrm{~mm}$. To make the open tube, an opening of $3.17 \mathrm{~mm}$ wide was cut in one of the tubes along the weld seam. As is shown on figure 4, a mounting apparatus to hold the tubes in such a way that the moment arms would be identical was built and the tubes were loaded in bending as well as in combined bending and torsion.

Three strain gauges were attached (orientated at $0^{\circ}, 45^{\circ}$, and $90^{\circ}$ with respect to the axial direction of the tubes) at identical points on the two tubes and were wired as shown on figure 5 . An Omega DMD-21 single channel digital strain indicator was used for strain measurements. Next, to impose a bending moment (without twist) a transverse load of $49.6 \mathrm{~N}$ was applied at the tip of each tube (using a high tension fishing lead) at $307 \mathrm{~mm}$ distance to the axial strain gauges and strain results were reported. To impose the combined bending and torsional loading, the same force was then applied at the 3 o'clock location on the side of each tube. In this way, a combination of torsion and bending was applied using a hose clamp orientated with the tightening mechanism parallel to the ground. The strain results were then recorded from the strain indicator and analyzed using the following procedure. 


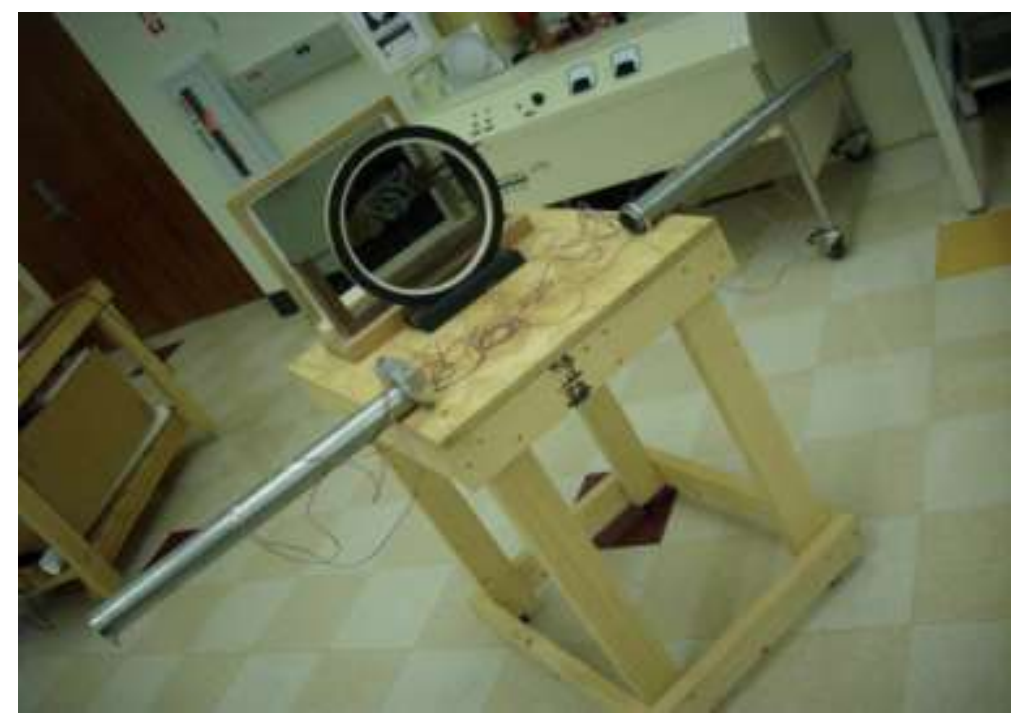

Figure 4 . Open and closed tube test setup for application of torsion and bending

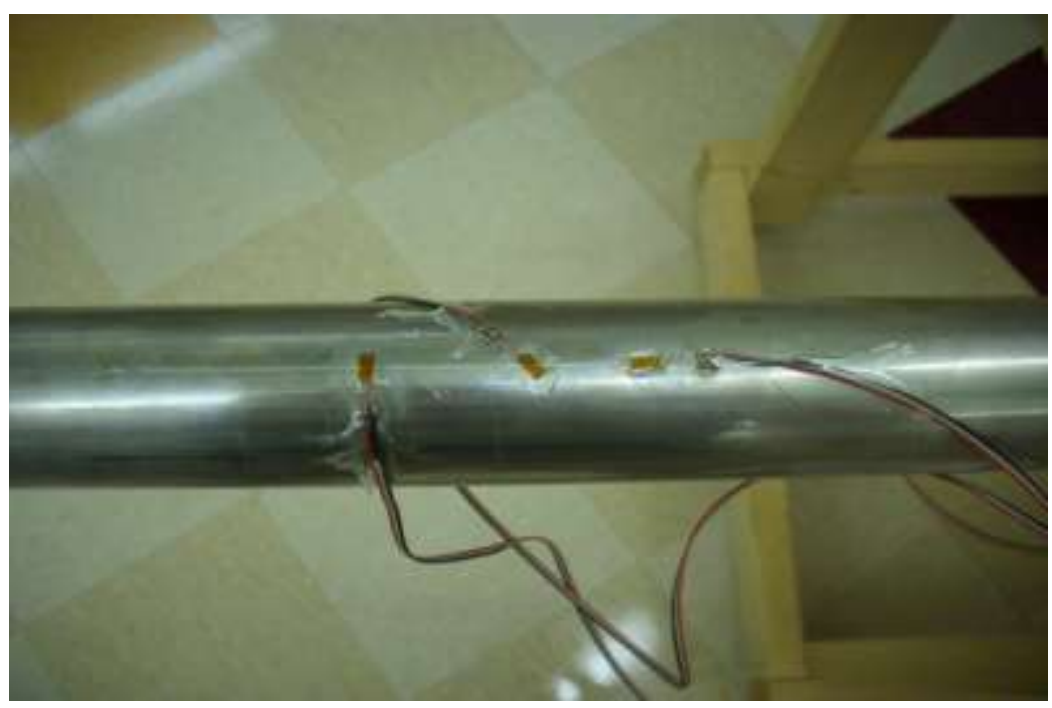

Figure 5. The three strain gauge sensors orientated at $0^{\circ}, 45^{\circ}$, and $90^{\circ}$

\section{Bending}

The second moment of area $(I)$ of a thin-closed round tube is given by,

$I=\pi \frac{\left(d_{o}{ }^{4}-d_{i}{ }^{4}\right)}{64}$

where $d_{o}$ and $d_{i}$ are the outer and inner tube diameters, respectively. Using this value for the second moment of area in equation (2) yields,

$\sigma=\frac{64 d W C_{R}}{\pi\left(d_{o}{ }^{4}-d_{i}{ }^{4}\right)}$ 
where, $W$ is the weight of the applied load, $c_{R}$ is equal to half of $d_{o}$ and $d$ is the axial distance between the load and the axial strain gauge.

Now, by substituting equation (7) into (1) the modulus of elasticity can be calculated as,

$E=\frac{64 d W C_{R}}{\pi \varepsilon_{x}\left(d_{o}{ }^{4}-d_{i}{ }^{4}\right)}$

\section{Torsion Combined with Bending}

While the two tubes act almost identically in bending, their behavior is different in torsion. The shear stress for a closed cylindrical tube is ${ }^{10}$,

$\tau=\frac{T c_{R}}{J_{c}}$

where $T$ is the applied torque, and for a closed tube, the torsional constant $J_{\mathrm{c}}$ is equal to the polar moment of area and is given by,

$J_{c}=\pi \frac{\left(d_{o}{ }^{4}-d_{i}{ }^{4}\right)}{32}$

For an open tube, the torsional constant is different from the polar moment of area and it is equal to,

$J_{o}=\frac{2}{3} \pi t^{3} c_{R}$

where $t$ is the thickness of the tube wall. The maximum shear stress can be expressed as,

$\tau=\frac{T t}{J_{o}}$

The applied torque, $T$, is given by,

$T=\left(c_{R}+t_{c}\right) \times W$

where, $t_{c}=1.86 \mathrm{~mm}$, is the eccentricity of the point of load application from the surface of the tube.

For both tubes, having the normal strain values at the three strain gauge locations, the principle stress values can be calculated by the flowing formula ${ }^{9}$

$$
\sigma_{1,2}=E\left[\frac{1}{2(1-v)}\left(\varepsilon_{A}+\varepsilon_{C}\right) \pm \frac{1}{2(1+v)} \sqrt{\left(\varepsilon_{A}-\varepsilon_{C}\right)^{2}+\left(2 \varepsilon_{B}-\varepsilon_{A}-\varepsilon_{C}\right)^{2}}\right]
$$

where $\varepsilon_{A}, \varepsilon_{B}, \varepsilon_{C}$ are the strain values corresponding to $0^{\circ}, 45^{\circ}$, and $90^{\circ}$ strain gauge orientations on the tubes. Shear strain, $\gamma_{x y}$, is calculated using,

$\gamma_{x y}=2 \varepsilon_{B}-\varepsilon_{A}-\varepsilon_{C}$ 
For the case of open tube, the shear strain is calculated as, $39.497 \mu \mathrm{rad}$, and the corresponding value for the closed tube is, $3.5 \mu \mathrm{rad}$. The reason of this difference is that the open tube has a much less value of torsional constant compared to the closed one. Calculation of the shear modulus is done by finding the ratio of shear stress and shear strain and it provides, $62.3 \mathrm{GPa}$.

\section{Maxwell's Reciprocity Theorem}

Maxwell's reciprocity theorem is a fundamental theorem in solid mechanics and is valid in the linear elastic region. Referring to figure 6 , this theorem states that if a load is applied at point $B$ on a specimen and the deflection is measured at point $C$, then the load is moved to point $C$ and deflection is measured at $B$ the two deflection values will be the same. One of the most important applications of this theorem is the symmetry of stiffness matrices in finite elements method. Due to this symmetry, only almost half of the elements of these matrices need to be calculated.

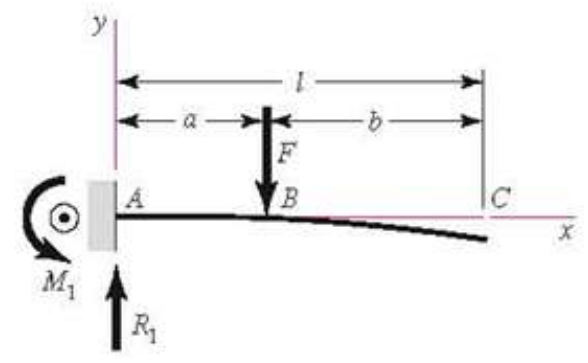

Figure 6. Cantilever beam with applied load $(F)$ at $B$ and deflection measurement at $C^{11}$
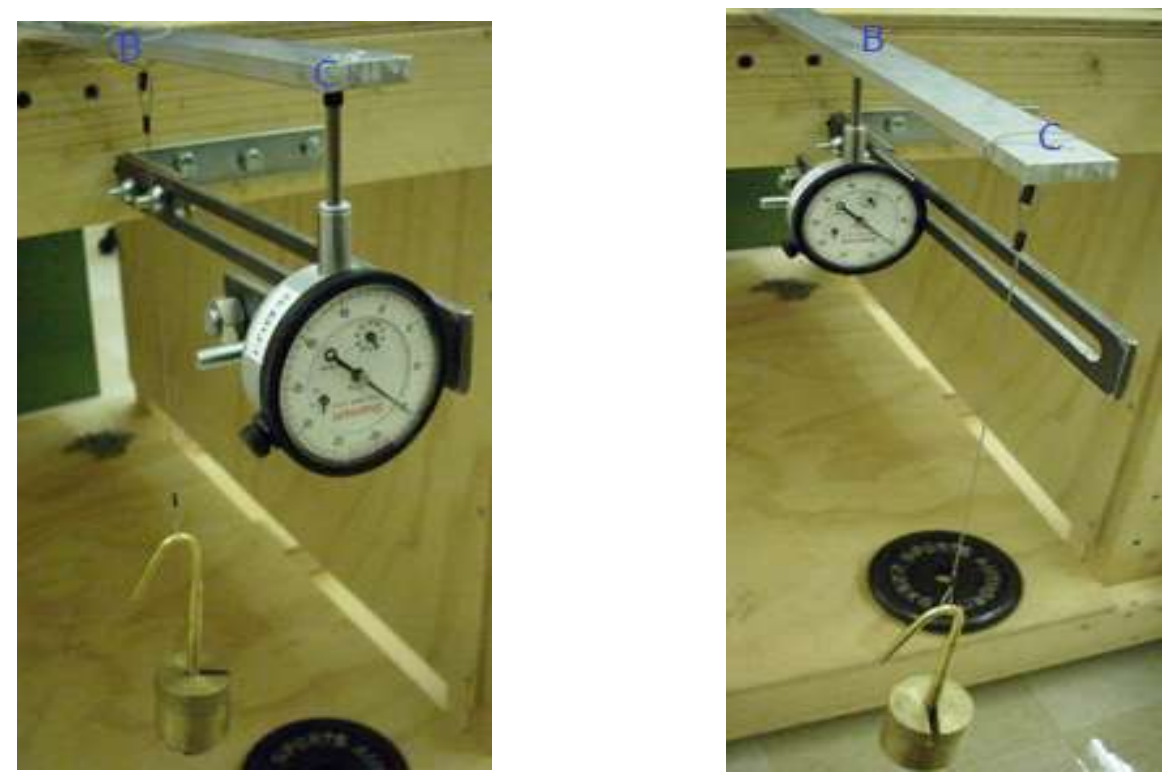

Figure 7. Maxwell's reciprocity theorem test setup with load $\mathrm{F}$ applied at position $B$ and deflection measured at $C$ (left), the load at position $C$ and deflection measured at $B$ (right). 
In this part of the experiments, a test setup is designed and built in order to demonstrate the validity of Maxwell's Reciprocity Theorem. A cantilever aluminum beam is assembled and loaded sequentially at two points $B$ and $C$ and the deflection values are measured at these points. To provide accurate measurements of the beam deflection, a Starrette model 631-J dial gauge is incorporated into the design. The manufacture of the mentioned design was performed using a Bridgeport end mill. Proper placement of the gauge at the beam's axial center line and perpendicular to the beam is crucial for the accuracy of the measurements. As shown on figure 7, a track mechanism to move the dial gauge forward and backward along the center-line of the beam is also added to the design. The gauge arm and bracket are mounted to the table at a suitable location where the gauge has almost $1 \mathrm{~mm}$ initial compression. A hanger for the load was then designed, spun on a lathe, and bent to shape. A weight of $3.48 \mathrm{~N}$ was applied to point $B$ (at $x_{\mathrm{BC}}=0.15 \mathrm{~m}$ from the tip of the beam) and deflection was measured at point $C$ (located at the tip). Then the procedure was repeated with the same load at $C$ and deflection measurements made at $B$. The two sets of data are reported in table 2 and a typical error percentage of around $5.7 \%$ is observed.

The deflection values can also be calculated theoretically using the deflection curve equation. The equation for determining beam tip deflection (at point $C$ ) when the load is applied at $B$ is

$y(x)=\frac{F}{6 E I}\left(-x_{B C}{ }^{3}+3 L^{2} x_{B C}-2 L^{3}\right)$

where $\boldsymbol{F}$ is the applied load, $x_{B C}$ is the distance between points $B$ and $C, \boldsymbol{L}$ is the total length of the beam, and $I$ is the second moment of area of the beam cross-section ${ }^{11}$.

Table 2. Maxwell's Reciprocity Theorem test setup data

\begin{tabular}{|c|c|c|c|}
\hline \multicolumn{4}{|c|}{ Chosen values in design } \\
\hline$F(\mathbf{N})$ & $L(\mathbf{m})$ & $x_{B C}(m)$ & $I\left(\mathrm{pm}^{4}\right)$ \\
\hline 3.47 & $0.3 \mathrm{~m}$ & $0.15 \mathrm{~m}$ & 542 \\
\hline \multicolumn{4}{|c|}{ Measured Deflection } \\
\hline \multicolumn{4}{|c|}{$\%$ Difference } \\
\hline $\begin{array}{l}\text { Load } \\
@ \mathbf{C}\end{array}$ & $196.9 \mu \mathrm{m}$ & 5.7 & \\
\hline \multicolumn{4}{|l|}{$\begin{array}{l}\text { Load } \\
@ B\end{array}$} \\
\hline \multicolumn{2}{|c|}{ Calculated Deflection } & \multicolumn{2}{|c|}{$\begin{array}{l}\text { \% Difference w/ trial vs. } \\
\text { Calculation }\end{array}$} \\
\hline \multirow{2}{*}{\multicolumn{2}{|c|}{$257.3 \mu \mathrm{m}$}} & $\begin{array}{l}\text { Load } \\
@ \mathbf{C}\end{array}$ & 23.5 \\
\hline & & $\begin{array}{l}\text { Load } \\
@ B\end{array}$ & 19.8 \\
\hline
\end{tabular}


Using equation (16), the corresponding theoretical deflection of the beam at either point in the yaxis is calculated to be $0.26 \mathrm{~mm}$.

\section{Destructive Tensile Testing}

In this part of the experiments, tensile test samples were manufactured using the ASTM E- 8 standard (table 3). The samples are 8-in long, 0.75-in wide and 0.25-in thick and have been made from C1018 cold rolled steel, 6061 Aluminum, and A36 hot-rolled steel. The manufacturing process for the samples involved using a Bridgeport end mill and a fixture to produce consistentrepeatable pieces (figure 8). Two inches apart gauge marks were placed on the samples to demonstrate the gauge length. Thirty six samples were machined: sixteen cold rolled steel, ten hot rolled steel, and ten aluminum samples.

Table 3. ASTM E-8. standard test methods for tension testing of metallic materials.

\begin{tabular}{|c|c|c|c|}
\hline \multicolumn{4}{|c|}{ Dimensions } \\
\hline & \multicolumn{2}{|c|}{ Standard Specimens } & Subsize Specimen \\
\hline & Plate-Type, $11 / 2$-in. Wide & Sheet-Type, $1 / 2-$ in. Wide & $1 / 4$-in. Wide \\
\hline & in. & in. & in. \\
\hline $\begin{array}{l}\text { G-Gage length (Note } 1 \text { and Note 2) } \\
\text { W-Width (Note } 3 \text { and Note 4) } \\
\text { T-Thickness (Note 5) } \\
R \text { - Radius of fillet, min (Note 6) } \\
\text { L-Over-all length, (Note 2,Note } 7 \text { and Note 8) } \\
\text { A-Length of reduced section, min } \\
\text { B-Length of grip section, (Note 8) } \\
\text { C-Width of grip section, approximate (Note } 4 \text { and Note 9) }\end{array}$ & $\begin{array}{l}8.00 \pm 0.01 \\
11 / 2+1 / 8,-1 / 4 \\
1 \\
18 \\
9 \\
3 \\
2\end{array}$ & $\begin{array}{l}2.000 \pm 0.005 \\
0.500 \pm 0.010 \\
\text { thickness of material } \\
11 / 2 \\
8 \\
21 / 4 \\
2 \\
3 / 4\end{array}$ & $\begin{array}{l}1.000 \pm 0.003 \\
0.250 \pm 0.005 \\
11 / 4 \\
4 \\
11 / 4 \\
11 / 4 \\
3 / 6\end{array}$ \\
\hline
\end{tabular}

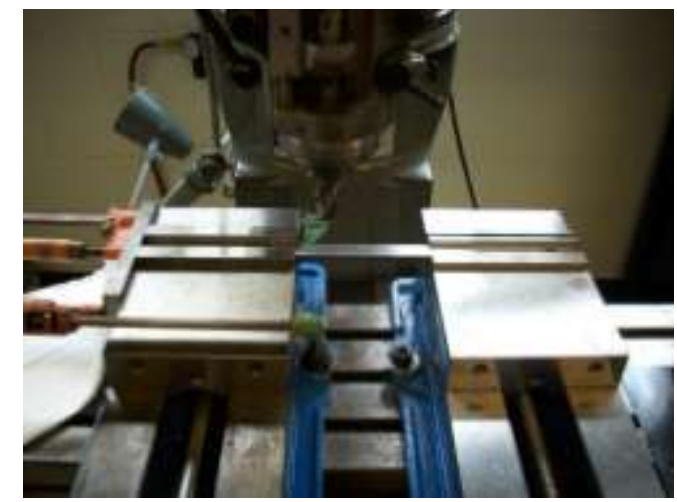

Figure 8. Fixture to hold the blanks while being machined into tension test samples by the mill 


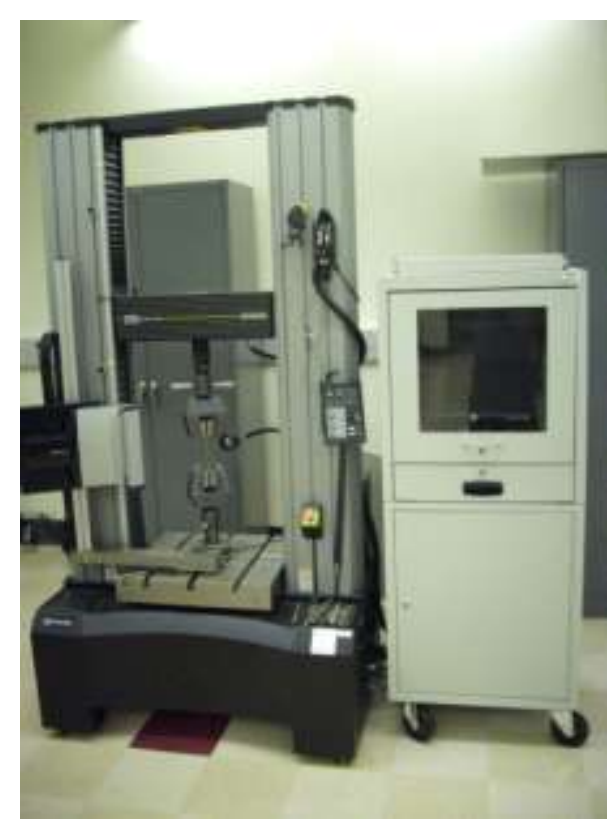

Figure 9. Instron universal testing machine model 5882

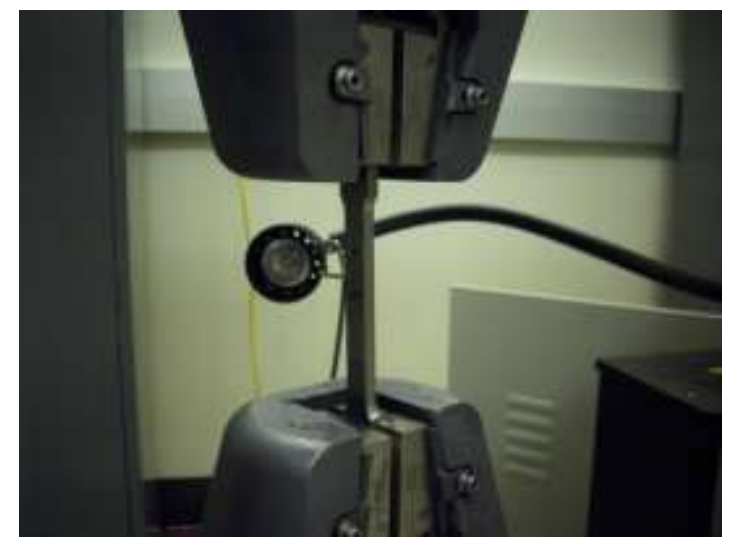

Figure 10. ASTM sample placed in the jaws of the Instron machine for tensile testing

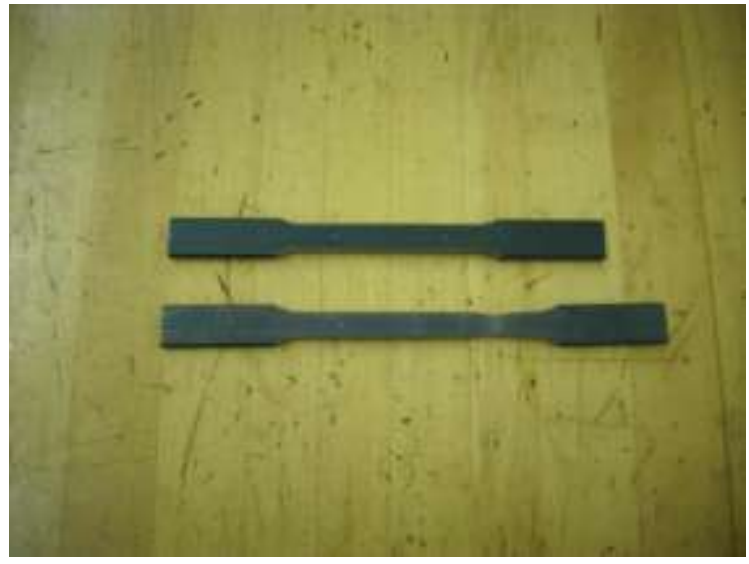

Figure 11. Comparison of an ASTM hot-rolled steel sample before and after tensile test 
Three samples, one of each material, were then tested on an Instron 5882 universal testing machine (figures 9 and 10) and the data was recorded. The normal strain in the samples was measured by an extensometer that was attached at the surface of the samples. The engineering normal stress was calculated by dividing the load cell reading by the original cross-sectional area.

Figure 11 demonstrates a hot-rolled steel sample before and after the tensile test. The engineering stress-strain diagrams of aluminum and hot rolled steel are shown on figures 12 and 13, respectively. The resulting mechanical properties of these materials have been listed on tables 4 and 5. These include modulus of elasticity, ultimate strength, yield strength, and rupture point. The modulus of elasticity of each material has been compared to the corresponding values from the bending of flat bar test discussed before. As is seen on tables 4 and 5, the results obtained from these two methods are much closer to each other for the Aluminum samples.

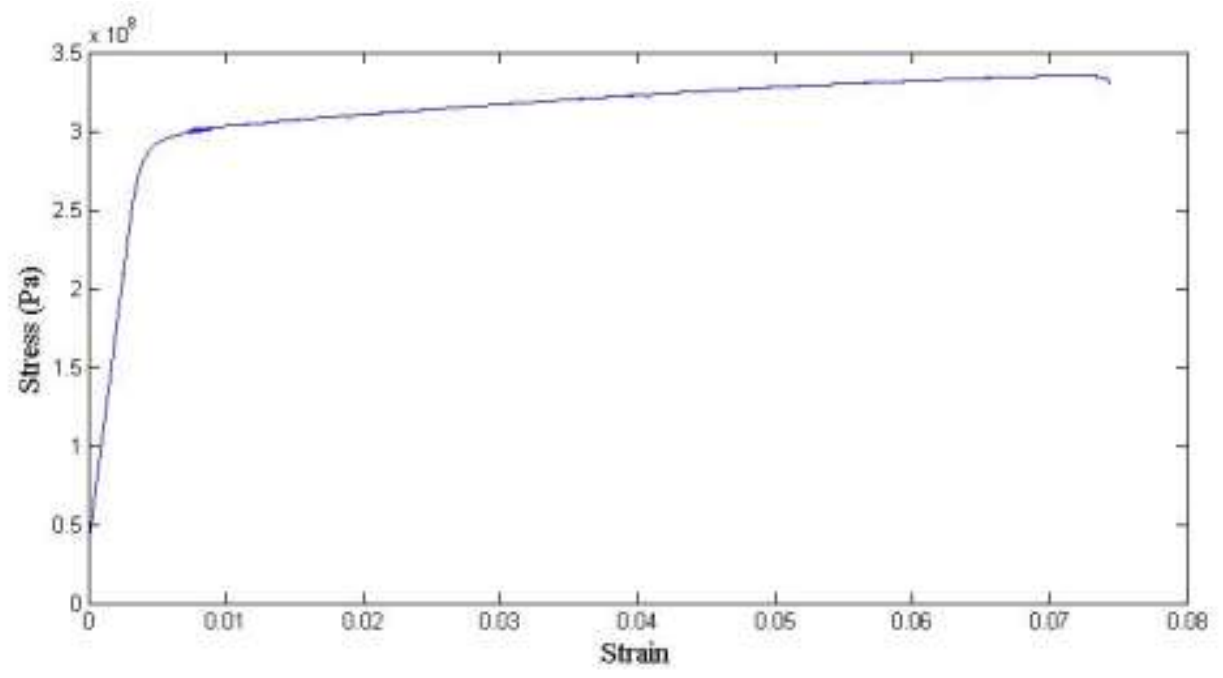

Figure 12. Stress versus strain curve for Al 6061

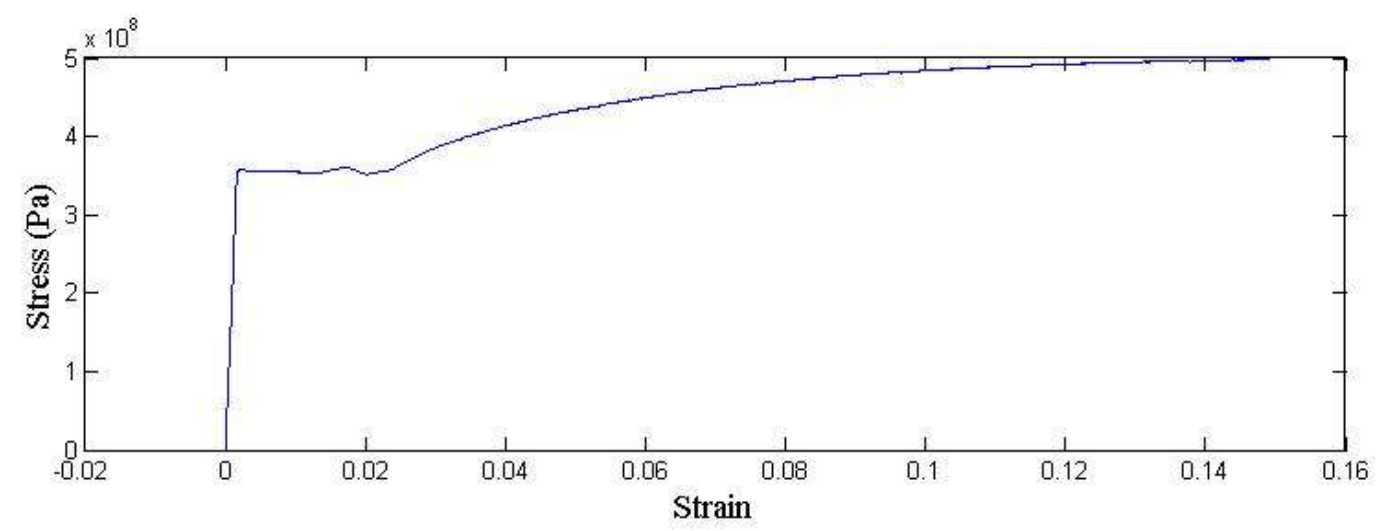

Figure 13. Stress versus strain curve for A36 hot-rolled steel 
Table 4. Tensile test of hot-rolled A36 steel on universal testing machine

\begin{tabular}{|c|c|c|c|}
\hline \multicolumn{4}{|c|}{ Hot rolled steel (A36) } \\
\hline Area $\mu\left(m^{2}\right)$ & & $\Delta \sigma(\mathrm{MPa})$ & $\Delta \varepsilon$ \\
\hline 80.138 & & 326.5 & 0.00157 \\
\hline $\begin{array}{l}\mathrm{E}(\mathrm{GPa}) \\
\text { (tensile test) }\end{array}$ & $\begin{array}{l}\mathrm{E} \text { (GPa) } \\
\text { (bending test) }\end{array}$ & $\%$ difference & Rupture Point (MPa) \\
\hline 208 & 190.13 & 8.6 & 498 \\
\hline \multicolumn{2}{|c|}{$\begin{array}{l}\text { Tensile Strength (MPa) } \\
\text { (Measured) }\end{array}$} & $\begin{array}{l}\text { Tensile Strength (MPa) } \\
\text { (literature) }\end{array}$ & $\%$ difference \\
\hline \multicolumn{2}{|c|}{498} & 550 & 9.5 \\
\hline \multicolumn{2}{|c|}{$\begin{array}{l}\text { Yield Strength (Mpa) } \\
\text { (Measured) }\end{array}$} & $\begin{array}{l}\text { Yield Strength (MPa) } \\
\text { (literature) }\end{array}$ & $\%$ difference \\
\hline \multicolumn{2}{|c|}{360} & 250 & 30.6 \\
\hline
\end{tabular}

Table 5. Tensile test of Aluminum 6061 on universal testing machine

\begin{tabular}{|c|c|c|c|}
\hline \multicolumn{4}{|c|}{ Aluminum (6061) } \\
\hline Area $\mu\left(m^{2}\right)$ & & $\Delta \sigma(\mathrm{MPa})$ & $\Delta \varepsilon$ \\
\hline 59.148 & & 204 & 0.00304 \\
\hline $\begin{array}{l}\text { E (GPa) } \\
\text { (tensile test) }\end{array}$ & $\begin{array}{l}\text { E (GPa) } \\
\text { (bending test) }\end{array}$ & $\%$ difference & Rupture Point (MPa) \\
\hline 67.11 & 63.2 & 5.8 & 358 \\
\hline \multicolumn{2}{|c|}{$\begin{array}{l}\text { Tensile Strength (MPa) } \\
\text { (Measured) }\end{array}$} & $\begin{array}{l}\text { Tensile Strength (MPa) } \\
\text { (literature) }\end{array}$ & $\%$ difference \\
\hline \multicolumn{2}{|c|}{330} & 310 & 6.1 \\
\hline \multicolumn{2}{|c|}{$\begin{array}{l}\text { Yield Strength (Mpa) } \\
\text { (Measured) }\end{array}$} & $\begin{array}{l}\text { Yield Strength (MPa) } \\
\text { (literature) }\end{array}$ & $\%$ difference \\
\hline \multicolumn{2}{|c|}{285} & 276 & 3.2 \\
\hline
\end{tabular}

\section{Effectiveness of Activities in the URF's Learning}

The experiments designed and implemented in this activity helped the first author (the URF) understand the concepts presented in strength of materials and design of machine elements. In particular, regarding the flat bar bending experiment, and the Poisson's ratio effect, obtaining a negative strain result and actually seeing how this is achieved on the transverse direction helped him better understand the physical meaning of strain in various directions.

During the summer URF, supervision and direction was continuously provided by the second author either face to face or by email. In these discussions the principles behind each of the proposed experiments were discussed and a plan of implementation was developed. Regular meetings on the design, manufacture, testing and analyzing the results stretched during the eight 
weeks period of this activity. The URF designed and built all the apparatus contained herein with continuous supersivion provided by his mentor.

Design, manufacture and testing of these experimental apparatus were effective in educating the URF in several other ways as well. These activities helped him better understand the mechanical design process as a whole and at the same time educated him about the way he can use several machine tools including milling machines and a lathe.

As to the cost, the design and implementation of these instructional devices were much less expensive than purchasing prefabricated equivalent devices. At the same time, a simple purchase would not provide all other benefits that a student like the first author could gain during a summer activity.

\section{Effectiveness in the Students' Learning}

The design of machine elements course at USM has three main components. One is three hours of lecture per week and the other is one hour of computer simulation (using SolidWorks) or one hour of hands on experiments in the mechanical engineering lab. Using these three different methods (theory, simulation and experiment) students learn how to verify the results that they obtain by one method with those they get by another method and verify their findings. Another activity in the course is a hands-on term project that includes the design and manufacture of a mechanical system or machine. Students also use a rapid prototyping machine for manufacturing their design ideas.

In the fall 2012 semester, students in the machine design course used the experiments that were explained in this paper (except for the round tube ones) as a part of their hands-on experience. They worked in the mechanical engineering lab and in groups of 3-4 students. The groups worked on different experiments and wrote lab reports that detailed their findings. It was the first time that the course was offered this way and therefore it was new for both the students and for the instructor (the second author). While in the lab students worked in groups, lab reports were required to be written by each student individually. A report for each experiment was asked to be written that summarized the following items,

1. Description of the importance of the experiment

2. The devices used and their functionalities

3. The test procedure

4. The collected data and related figures and graphs

5. The obtained experimental results

6. The theoretical solution of the same problem (if available)

7. Comparison of the experimental and the theoretical results and discussion on the reasons of any differences (if applicable) 
The effectiveness of these experiments was closely monitored by the instructor and also was evaluated by formal anonymous questionnaires. A questionnaire that was given to the students at the end of the semester included 15 questions on various aspects of the course. One question was related to the laboratory experience. It is, "How do you feel about the laboratory experience that you had in the course?" Here are a few answers (total number of completed forms: 22),
a. Kind of a bit much work
b. Very relevant to the class
c. More SolidWorks time would have been great
d. The course should have focused more on SolidWorks
e. Excellent ( 3 answers)
f. Good (9 answers)
g. Fair (4 answers)
h. Poor ( 2 answers $)$

So, it may be observed that while students enjoy learning more effectively using hands on experiments, some of them feel that in a three credit course, it would require them to do a lot of work. A few of these experiments will no longer be given in the mentioned course and instead will be parts of the experiments done in strength of materials. In fall 2012 these experiments were given in the machine design course to make up for the lack of such experiments when those students took the strength of materials course.

In the current semester (spring 2013), a few of these experiments are now part of the strength of materials course (taught by the second author). Another anonymous questionnaire has been given to these students in the beginning of the semester and here are the results,
a. Having lab experiments that coincide with lecture material would be helpful
b. Labs are not necessary
c. I look forward to it
d. I wouldn't mind a few labs
e. Good idea! Helps understand the material
f. Excellent (3 answers)
g. Good (5 answers)
h. Fair (1 answer)

\section{Lessons to be Learned}

The experiments that were developed in this study are not new, but they did not exist in the university where the authors are located at. The main reason for this activity was to develop these experiments for the benefit of students that take solid mechanics courses. Another reason was to train a URF and direct him on how to design, manufacture and perform these tests. A final advantage of performing this activity was to obtain a variety of experimental devices with minimal cost. 
This activity can certainly be replicated in other institutes. The main required resource is a dedicated student who wants to learn more during a summer break. Also, a faculty member would be needed to supervise and guide the student and answer his/her questions. Furthermore, there are some materials and equipment that would be needed for setting up the experiments. A list of these materials and equipment can be obtained by reviewing various sections of this paper. Finally, since many of the developed experiments require some machining, a machine shop with milling and lathe machines would be needed.

The responses that were received from the students (mentioned in section 8) might be helpful for other educators as well. It is evident that many students like hands-on experiments as required supplements to their formal engineering education. They look at this activity as the one that reinforces their learning of theories. However, many of them do not like to spend a lot of time writing lab reports and also prefer to have labs that coincide with the concepts that are being taught at the same time. Fulfilling this last wish in relatively small laboratories is not easy. In fact, due to having only one test setup for each experiment, students cannot use the same test setup in each lab period. So, they have to work in parallel on experiments that some of them have not been formally discussed about in lectures. While it is an important shortcoming, it can also provide an advantage by persuading students to get ready for the lectures that are forthcoming. So, instead of first listening to the lecture and then do the lab they can experience in the lab first and then, with having some physical understanding on the subject, listen to the lecture and learn the theories much better.

\section{Conclusion}

This paper summarizes the activities of a summer Undergraduate Research Fellow (URF) and the way the outcome of his work is being used for providing laboratory experience for students in strength of materials and design of machine elements. As a result of this fellowship, among other activities, four devices have been designed, fabricated and tested. The first one has been developed for measuring the modulus of elasticity and Poisson's ratio of a few metallic samples. These material properties have been obtained in a bending test by measuring the normal strain using two strain gauges located along and perpendicular to the longitudinal axis of a beam member made of the materials of interest. The same properties have also been measured using a tensile test of ASTM standard samples. Performing these experiments provides a long-lasting understanding for students about what the physical meanings of modulus of elasticity and Poisson's ratio are. In another part of this activity, a test setup was built to demonstrate a very fundamental theorem, i.e. Maxwell's Reciprocity theorem. This test provides students with a physical understanding of this theorem and helps them realize what it really means and verify its validity. The behavior of closed and open thin-walled members was compared using another test 
setup and the corresponding shear strain values in torsion were measured. Finally, a test setup for analyzing stress patterns in a sample using photoelasticity was built.

Starting from fall 2012, these devices have been used by students as part of the hands-on labs that are integrated with the mentioned courses. The received feedback from students has been mostly positive as they stated that they enjoy learning the course material much more if it is accompanied with such hands on activities. However, students also prefer to have labs that coincide with the concepts that are being taught. Implementing this last wish in relatively small laboratories is not easy. In fact, by having only one test setup for each experiment, not all students can use the same test setup in each lab period. While it is an important shortcoming, it can also provide an advantage by making students ready for the lectures that are forthcoming. So, instead of first listening to the lecture and then do the lab they can experience lab first and then with having some physical understanding on the subject, listen to the lecture and learn the theories much better.

\section{Acknowledgements}

The authors are grateful to Mr. Chad Seeley who is the Laboratory Associate at USM. His

assistance in the manufacture of the experimental devices that were built in the course of this research is greatly appreciated.

\section{References}

1. N. Randall and M.Ghorashi, "Design, Manufacture, Simulation and Experimentation of Several Tools to Assist in Teaching Strength of Materials and Statics Courses," $119^{\text {th }}$ ASEE Annual Conference, San Antonio, TX, June 10-13, 2012, Paper number: AC 2012-2971 (2012).

2. J.E.Corter, S.K.Esche, C.Chassapis, J.Ma and J.V.Nickerson, "Process and Learning Outcomes from Remotely-operated, Simulated, and Hands-on Student Laboratories," Computers \& Education, 57 (2011) 2054-2067.

3. A. Ayob, A. Hussain, M.M. Mustafa, M.F.A.S. Shaarani, "Nurturing Creativity and Innovative Thinking through Experiential Learning," Procedia Social and Behavioral Sciences, 18 (2011) 247-254.

4. M.G.Mehrabi, "Lab System Design in Support of Manufacturing Engineering Curricula," Journal of Manufacturing Systems, 24 (2005) 251-255.

5. D. Mateo-Ortiz, D.A.Mota-Aguilar, M.A.Florian-Algarin, S.L. Aviles-Barreto, R. Mendez, C. Velazquez and N.Cardona-Martinez, "Motivating K-12 Students to Study Pharmaceutical Engineering using Guided Hands-on Visits," IChemE Education for Chemical Engineers, 7 (2012) e219-e229.

6. M. Abdulwahed and Z.K. Nagy, "The TriLab, a Novel ICT based Triple Access Mode Laboratory Education Model," Computers \& Education, 56 (2011) 262-274.

7. C.A.Jara, F.A.Candelas, S.T.Puente, and F.Torres, "Hands-on Experiences of Undergraduate Students in Automatics and Robotics using a Virtual and Remote Laboratory," Computers \& Education, 57 (2011) 2451-2461. 
8. J.V.Nickerson, J.E.Corter, S.K.Esche and C.Chassapis, "A Model for Evaluating the Effectiveness of Remote Engineering Laboratories and Simulations in Education,” Computers \&Education, 49 (2007) 708725.

9. J.W. Dally and W. F. Riley, Experimental Stress Analysis, second edition, McGraw-Hill, NY (1978).

10. F.P. Beer, E.R. Johnston Jr, J.T. DeWolf, and D.F. Mazurek, Statics and Mechanics of Materials, McGrawHill, NY (2011).

11. R.G. Budynas and J.K. Nisbett Shigley's Mechanical Engineering Design, ninth edition, McGraw-Hill, NY (2011). 